\title{
O PROCESSAMENTO DO CONCEITO "SISTEMATIZAÇÃO DO CUIDAR": UMA ETAPA PARA A CONSOLIDAÇÃO DA INTERVENÇÃO DO ENFERMEIRO.
}

Cilene Aparecida Costardi Id!'

Irene? Kreutz*

IDE, C.A.C.; KREUTZ, I. O processamento do conceito "sistematiłaçao do cuidar": uma etapa para a consolidaçáo da intervençăo do enfermeiro. Rev.Ese.Enf. USP. v.29, n.3, p. 310.16, dez. 1995.

O trabalho analisa o processo de implementação de uma disciplina de graduação que tem como núcleo a sistematizaşão do cuidar do adulto instilucionalizado.

Unitermos: processo ensino-aprendizagem: processo de cuidar

\section{INTRODUÇÃO}

A exploração do processo de implementação de uma nova estrutura curricular pressupõe a identificação de estratégias habilitadas a apreender redes de significações e de vivências em constante formação e transformação.

Nesse sentido, a internalização dos valores, dos conceitos, dos prinćpios e das ações que modulam e conformam o padrão de formação privilegiado pelo currículo, configura ritmos peculiares de adesão de docentes e discentes a nova proposta, produzindo formas fundamentalmente inéditas de respostas e de atuações desses sujeitos, estabelecendo etapas de construção e de reconstrução da proposta inicial a serem apreendidas e analisadas.

Frente a essa concepção c tendo como premissa a proposição de um novo padrão de formação do enfermeiro assistencial, aqui reconbecido como o profissional com competência para coordenar o processo de cuidar, atividade

* Doutora do Departamento de EnfermagemMédicu-cirúrgica, orientadora de estágio no Programa de Aperfeicoamento de Ensino.

* Enfermeira do Hospital Alemno Oswaldo Cruz. doutoranda na F.EUSP, bolsista do Programa de Aperfeiçoamento de Ensino. 
que agrega a sistematização do cuidar, o relacionamento com as equipes e com o contexto institucional ${ }^{* * *} e$ identificando a avaliação clínica como o cerne da etapa da instrumentalização do estudan te no âmbito da atuação assistencial do enfermeiro, desenvolvemos este trabalho que tem como objetivo:

- caracterizar o processo de internalização do ideário da disciplina Fundamentação do Processo de Cuidar, ao sistema de atuação docente.

\section{METODOLOGIA}

Esta pesquisa foi desenvolvida no ano de 1994 , junto a 16 dos 25 docentes do Departamento de Enfermagem Médico-cirúrgica (ENC) de uma Escola de Enfermagem da rede pública do estado de São Paulo, responsáveis pelo desenvolvimento de disciplinas que no currículo mínimo anterior eram inseridas no tronco profissional comum, ou seja, Fundamentos de Enfermagem e Enfermagem Médico-cirúrgica. Também fizeram parte do estudo docentes da disciplina de Enfermagem em Centro Cirúrgico e em Centro de Material por dois motivos: por estarem inseridos no mesmo departamento e, principalmente, porque o novo currículo, vigente nessa escola desde 1994, tem a sua estrutura pautada $\mathrm{cm}$ macro áreas temáticas que superaram a organização curricular compartimentalizada em disciplinas isoladas. Nessa programação, todos os docentes participantes são responsáveis, no âmbito da graduação e da pos-graduação, pelas disciplinas que tem como objeto de atuação a Saúde do Adulto Institucionalizado, excluindo desse contexto as mulheres no ciclo gravídico-puerperal, as pessoas com distúrbios psiquiátricos e aquelas portadoras de doenças transmissiveis, que apresentam as condições referidas como única manifestação.

Metodologicamente, este estudo pautou-se na análise de conteúdo de depoimentos docentes, tendo como núcleos temáticos:

. a análise acerca do programa de ensino da disciplina Fundamentação do Processo de Cuidar;

- as expectativas relativas ao aprendizado discente no transcorrer do processo de ensino da disciplina;

. as proposições relativas à condução e a avaliação discente frente ao programa de ensino proposto.

Vale salientar que essa disciplina, desenvolvida no primeiro ano de graduação, tendo 165 h de carga horária, é a primeira disciplina do currículo da EEUSP a abordar, a fundamentar e a iniciar o processo de instrumentalização teórico-prática do estudante no âmbito da prática assistencial do enfermeiro, tendo na avaliação clínica e na introdução ao processo de julgamento clínico, conteúdos privilegiados ainda que não exclusivos. 
Os discursos foram categorizados em núcleos temáticos comuns, configurando um contexto a ser descrito a seguir.

\section{RESULTADOS}

A análise do produto das apreciações docentes acerca do programa de ensino permite identificar uma polaridade "avancos-vazios", considerada sob diferentes prismas.

Quadro 1: Calegorias relativas ao alcance do programa de ensino da disciplina, Fundamentação do Processo do Cuidar

\begin{tabular}{|c|c|}
\hline AVANÇOS & VAZIOS \\
\hline $\begin{array}{l}\text { - superação do ensino pautado em } \\
\text { procedimentos isolados; } \\
\text { - compreensão da dimensão "macro" da } \\
\text { prática institucional (papel profissional, } \\
\text { processo de trabalho); } \\
\text { - releitura dos papéis (do ser doente, do ser } \\
\text { profissional); } \\
\text { - avaliação e a organização dos dados } \\
\text { obtidos como sendo a especificidade da } \\
\text { disciplina; } \\
\text { - nova sistematização de conteúdos } \\
\text { (inserção mais precoce à profissão, com } \\
\text { conformação inédita; eixo norteador do } \\
\text { ensino do departamento. }\end{array}$ & $\begin{array}{l}\text { - dominio de conteúdos ainda não } \\
\text { consolidados; } \\
\text { - instrumentos ainda não adequados aos } \\
\text { objetivos e métodos; } \\
\text { - diferenças quanto ao significado atribuido } \\
\text { a uma nova linguagem; } \\
\text { - conteúdos incoerentes frente aos } \\
\text { objetivos da disciplina. }\end{array}$ \\
\hline
\end{tabular}

A caracterização dos depoimentos identifica um movimento ainda periférico de validação do novo padrão de formação do enfermeiro.

Assim sendo, essa etapa de transição do modelo de formação, superando a instrumentalização enfaticamente centrada em procedimentos necessários ainda que nem sempre adequados e nem mesmo suficientes para o domínio do cuidar ao nível da atuação do enfermeiro, para um novo padrão, centrado na inserção no cenário de prática, na esfera das relaçōes profissionais inerentes a essa dinâmica e na sistematização do cuidar de todos os doentes inseridos nesse contexto passa a constituir um processo em maturação.

O discurso docente foi capaz de pontuar, ainda que isoladamente, contcúdos programáticos privilegiados pela disciplina. $\Lambda$ apropriação desse referencial, bem como a sua transformação num conteúdo intrapessoal, parece configurar um processo em desenvolvimento, ainda pautado em adesões 
parciais a esse ideário. Já identifica e valora positivamente as mudanças inseridas, com ênfase tanto na abrangência analítica como substrato para a intervenção, como tambem na avaliação enquanto instrumento privilegiado para a atuação assistencial do enfermeiro.

Entretanto, enquanto processo em construção, dificuldades foram identificadas. Algumas relativas à esfera operacional, sendo portanto, de resolutividade imediata. Outros, de ordem mais complexa na medida em que aprecndem os grandes desafios dessa proposta, ou seja, a convivência com diferentes códigos de atuação, manifesta na diversidade com que os docentes apreendem e nominam o seu objeto de intervenção; a confluência de diferentes propostas de atuação no âmbito do cuidar e, por decorrência, a identificação de distintas possibilidades e estratégias de ação.

Mais do que limites da proposta atual, esses vazios demonstram o sentido, a direção e abrangência do processo de validação do processo de cuidar do enfermeiro no âmbito do cuidar em Finfermagem. Esse será o desafio a ser bancado pelo sistema formador na medida em que superar o caráter idealizado de apreensão da realidade assistencial que clama por um enfermeiro apto a atuar com competência e com domínio técnico-científico ao nível da coordenação do cuidar.

O segundo aspecto apreendido neste estudo relaciona-se à esfera das expectativas docentes acerca do desenvolvimento discente, compondo um conteúdo referido a seguir:

Quadro 2: Categorias relativas às expectativas de desenvolvimento discente

\begin{tabular}{|c|c|}
\hline CAPACIDADE DISCENTE PRÉVIA & $\begin{array}{c}\text { CAPACIDADE DISCENTE AO FINAL } \\
\text { DA DISCIPLINA }\end{array}$ \\
\hline $\begin{array}{l}\text { - Conhecimentos: ciências biológicas, } \\
\text { psicológicas e sociais; } \\
\text { - Atitudes: envolvimento, responsabilidade, } \\
\text { participação, entusiasmo: } \\
\text { - Prontidão: para proteger-se, para prestar } \\
\text { primeiros socorros, procurar } \\
\text { oportunidades, definir objetivos; } \\
\text { - Compreensão: de papéis profissionais, do } \\
\text { contexto de saúde. }\end{array}$ & $\begin{array}{l}\text { - Compreensão do contexto de prática: } \\
\text { - Capacidade de coletar e organizar dados; } \\
\text { - Capacidade de avaliar, atribuindo } \\
\text { significados e objetivos à luz do } \\
\text { referencial teórico privilegiado; } \\
\text { - Atuação dentro dos limites de } \\
\text { biosegurança. }\end{array}$ \\
\hline
\end{tabular}

Na medida em que uma nova concepção de atuação profissional passa a ser requerida pela prática e identificada pelo ensino, uma nova proposta de formação se organiza, modificando-se a si mesma o ds disciplinas que the dão sustentação.

Nesse processo, a especificidade, a complexidade e a fundamentação 
teórico-prática propostas pela disciplina $\mathrm{cm}$ questão, reelaboram o nivel de pré requisitos necessários à inserção do aluno ao seu processo de ensino, conforme atestam as categorias referidas nesse quadro.

Vale salientar que a capacidade discente pressupõe uma reelaboração multifocal de possibilidades, agregando não somente a dimensão cognitiva como também a comportamental. Nesse sentido, para esses docentes, estar habilitado agregava: a compreensão do ser enfermeiro no âmbito das práticas de saúde; a fundamentação pautada em conteúdos das três areas do saber que dão sustentação à Enfermagem; uma atuação pautada em características profissionais a serem desenvolvidas no sentido do engajamento e da busca do auto desenvolvimento cientificamente sustentado.

Vale acrescentar que, inclusive nesse âmbito de análise, dúvidas foram novamente referidas, relacionando-se: ao truncamento ainda existente entre os diferentes temas que conformam o programa da disciplina, podendo comprometer a sua fundamentação e, ainda, quan to à apropriação e utilização subseqüente desse referencial pelo aluno no decorrer da própria graduação.

Frente a esse contexto, esquemas para a condução da disciplina foram propostos, estando relatados a seguir.

Quadro 3: Categorias relativas à proposição de estratégias para o desenvolvimento da disciplina Fundamentação do Processo de Cuidar

\begin{tabular}{|c|c|}
\hline DESENVOLVIMENTO & AVALIAÇÃO \\
\hline $\begin{array}{l}\text { - Articulação teórico-prática incluindo } \\
\text { conteúdos e carga horária; } \\
\text { - Encadeamento entre estratégias } \\
\text { pedagógicas: aula teórica - laboratório - } \\
\text { campo de prática - discussões - leituras; } \\
\text { - Retomadas sistematizadas de objetivos e } \\
\text { estratégias; } \\
\text { - Aprofundamento da reflexão acerca do } \\
\text { contexto de prática; } \\
\text { - Planejamento conjunto no âmbito da } \\
\text { disciplina e das outras áreas temáticas; } \\
\text { - Projeto de desenvolvimento do } \\
\text { Departamento no sentido de aprofundar } \\
\text { o dominio do seu objeto de ensino e de } \\
\text { prática. }\end{array}$ & $\begin{array}{l}\text { - Aprimoramento das estratégias } \\
\text { convencionais (provas, seminários); } \\
\text { - Estabelecimento de um contrato de } \\
\text { mútua responsabilidade: definição de } \\
\text { objetivos, definição de papéis, } \\
\text { expectativa de participação; } \\
\text { - Desenvolvimento de estratégias de } \\
\text { aprimoramento do processo de } \\
\text { elaboração cognitiva; } \\
\text { - Desenvolvimento da consciência } \\
\text { profissional }\end{array}$ \\
\hline
\end{tabular}


Esta etapa da categorização privilegia a esfera da operacionalização. Esta, por sua vez, também se organiza a partir das dúvidas e dos vazios a serem preenchidos no decorrer do processo.

Na proposição do sistema de avaliação três aspectos merecem destaque. O primeiro diz respeito à identificação de um novo patamar de relacionamento docente-discente, pautado no contrato mutuamente firmado, no sentido da delimitação de papéis, de atuação e de responsabilidades frente a um conteúdo teórico-prático a ser desenvolvido em conjunto. O segundo relaciona-se à necessidade de formulação de estratégias de acompanhamento do processo de desenvolvimento cognitivo do aluno na transição do nível de desenvolvimento potencial - determinado através da solução de problemas sob orientação - para o nível de desenvolvimento independente de problemas inerentes ao cuidar do adulto institucionalizado'.

Concomitantemente, o terceiro aspecto sugerido para a avaliação do aprendizado relaciona-se ao desenvolvimento de um conjunto de hábitos profissionais específicos, fruto da interação entre o ser aluno e o seu contexto prévio e o ser aluno inserido agora no contexto hospital - assistência ao adulto - relação com o outro e com uma dinâmica de trabalho $\mathrm{cm}$ saúde.

\section{CONSIDERAÇÕES FINAIS}

() momento de maior significação para o sistema formador, que dá origem a formas inéditas de interação ensino-prática, acontece quando, proposta a mudança, se implementa o projeto, avaliando respostas.

Aspectos dessa modificação ativa do projeto proposto como parte do processo de resposta a ele foram aqui caracterizados.

$\Lambda$ sua maturação pressupooe uma sêrie de transformações qualitativas e que criam condições para novas etapas de desenvolvimento, configurando estágios de um mesmo processo intencionalmente assumido pelos docentes responsáveis pela disciplina em estudo, compondo a história do desenvolvimento desse grupo.

Distintas são as frentes de trabalho. Evidenciou-se a necessidade de efetivamente validar um novo padrão de formação do profissional de nível superior, na tentativa de atender a um mercado de trabalho que tem a coordenação do cuidar em aberto. Nesse contexto, o enfermeiro assistencial convive com múltiplas atribuições ainda reconhecidas pelo sistema formador como desvios sendo, portanto, desconsideradas numa apropriação idealizada do seu objeto de trabalho, reiterando um vínculo também idealizado como o cuidado direto, prerrogativa de toda a equipe de enfermagem. Historicamente o sistema de ensino tem resistido à mudanças, sem considerar o papel e 
conseqüentemente a bagagem teórico-pratica necessária e suficiente para uma formação do enfermeiro em consonância com demandas efetivas do campo.

Hoje, já se identifica um caminho na direção de consolidar uma formação que, tendo na sistematização do cuidar uma prioridade, agregue a interação no âmbito tanto da cultura institucional quanto das relações profissionais como conteúdos e como práticas passiveis de serem ensinadas na medida $\mathrm{em}$ que efetivamente conformem o saber fazer enfermagem.

Evidentemente vazios foram identificados. Relacionam-se tanto à esfera da concepção quanto da operacionalização do modelo. Formar um novo profissional, tendo por responsabilidade a identificação do nível de desenvolvimento cognitivo, a intervenção pedagogica - acrescentando, modificando ou negando conteúdos, crenças e ações de saúde, o acompanhamento desse processo de elaboração de novos sistemas de conceitos e de consciência profissional, culminando na responsabilidade de validação de um sistema de avaliação ap to a apreender esse desenvolvimento de práticas e de hábitos profissionais, passou a se um desafio assumido pelo grupo de docentes na trajetória da consolidação do ensino e da prática do cuidar do adulto institucionalizado.

IDE, C.A.C.; KREUTZ, I. The concept "systematization of care": a phase to consolidate the nurse"s intervention. Rev.Ese.Fnf. USP. v.29, n.3. p. 310-16, dec. 1995.

The study analyse the implementation process of a discipline in Graduation Course which principal interest is "systematization of care to hospitalized adult".

UNITERMS: Teaching-apprenticeship process. Care process.

\section{REFERÊNCIAS BIBLIOGRÁFICAS}

1.VIGOTSKY, L.S.A. A formação social da mente: o desenvolvimento dos processos psicológicos superiores. 4. ed. Săo Paulo, Martins Fontes, 1991. 